\title{
A Amazônia e a fundação do Brasil na obra Simá (1857) de Lourenço da Silva Amazonas
}

\author{
The Amazon and the foundation of Brazil in the work Simá (1857) by Lourenço \\ da Silva Amazonas
}

\author{
Luís Francisco Munaro \\ Professor da Universidade Federal de Roraima \\ luis.munaro@ufrr.br
}

Resumo: Este artigo tem como objetivo situar a obra literária Simá - Romance histórico do Alto Amazonas (1857) de Lourenço da Silva Amazonas no interior da rede de interlocução de letrados do Instituto Histórico e Geográfico do Brasil, destacando as particularidades do entendimento do autor sobre a questão indígena e a construção da nação brasileira. $\mathrm{O}$ conceito de nação formulado por Benedict Anderson, como "comunidade política imaginada", orientará a investigação. Nossa hipótese de trabalho é que, revolvido no seio de elementos literários de época como o romantismo, a idealização da natureza e do indígena, Lourenço busca dar um sentido para a Amazônia e configurá-la como um dos elementos fundadores do Brasil. A investigação está organizada em torno de quatro seções: uma primeira destinada a identificar Lourenço no IHGB; uma segunda destinada a ler mais cuidadosamente o seu Diccionario topográfico, histórico e descriptivo da Comarca do Alto Amazonas (1852), buscando entender como reúne elementos históricos e etnográficos que permitem gerar uma percepção da região; por fim, as duas últimas buscam compreender como região e nação se fundem na composição da obra.

Palavras-chave: Lourenço Amazonas; Simá; Amazônia; Nação; história das ideias.

\begin{abstract}
This article aims to locate the literary work Simá - Historical novel of Alto Amazonas (1857) by Lourenço da Silva Amazonas within the network of literacy dialogue of the Historical and Geographic Institute of Brazil, highlighting the particularities of the author's understanding of the issue and the construction of the Brazilian nation. The concept of nation formulated by Benedict Anderson, as an "imagined political community", will guide the investigation. Our working hypothesis is that, revolved in the midst of literary elements of the time such as romanticism, the idealization of nature and the indigenous, Lourenço seeks to give meaning to the Amazon and configure it as one of the founding elements of Brazil. The investigation is organized around four sections: a first aimed at identifying Lourenço at the IHGB; a second, designed to read more carefully his topographic, historical and descriptive Dictionary of the Comarca do Alto Amazonas (1852), seeking to understand how it brings together historical and ethnographic elements that allow generating a perception of the region; finally, the last two seek to understand how region and nation merge in the composition of the work.
\end{abstract}

Keywords: Lourenço Amazonas; Simá; Amazonia; Nation; history of ideas. 
Manaus! Ao que temos chegado em nossa terra aos olhos dos europeus? Ao princípio negaram-nos a humanidade; e se hoje no-la toleram, não é senão para se divertirem no desfruto de nossos esforços para correspondermos a essa civilização, a que nos obrigam (Principal Mabbé, Simá, 2011: 270).

Ainda que a necessidade de contexto para a interpretação textual pareça hoje bastante evidente, não é incomum, nas leituras históricas, ver o texto sendo colocado no tribunal de julgamento do presente e seu autor classificado como reacionário por não corresponder às expectativas do intérprete. Muitas vezes esse é um tipo de leitura que Quentin Skinner teria classificado como doutrinal, baseada na tentativa de encontrar nos textos produzidos por agentes do passado um corpo de doutrinas completo, absolutamente coerente e, a partir dele, assumir aquilo que seria o ponto de vista da fonte, quando o que se está assumindo é o preconceito do próprio intérprete. É como se o autor interpretado devesse dizer alguma coisa e, quando não diz da forma como deveria ter dito, precise ser censurado pelo intérprete, que deixa de ser historiador e se transforma numa espécie de censor das limitações do horizonte do texto (SKINNER, 1969).

Apresenta-se assim o risco de que as nossas expectativas sobre o que alguém disse acabem transformando a ação do outro em algo que ele nem sequer teria aceitado ou muito menos teria sido possível dizer num determinado momento. Quentin Skinner tenta desfazer tanto a ideia de que obras passadas possuem "elementos atemporais" ou "ideias universais", quanto busca compreendê-las em função da tradição na qual elas se inscrevem e do que intencionaram dizer (SKINNER, 1969). O texto interpretado possui as suas próprias indagações, seu próprio questionamento da realidade, e é mais bem compreendido na condição do que John Austin chamou de "ato de fala" (1990), como um gesto destinado a interferir na visão de interlocutores. O maior risco para a compreensão, ainda segundo Skinner, é a projeção dos preconceitos do intérprete sobre a obra, sufocando qualquer possibilidade de seu entendimento. O processo de leitura e análise envolve, assim, um desnudamento dos próprios preconceitos, considerando que o intérprete também está inscrito num tempo e possui expectativas diferentes daquelas da obra analisada.

Dentre os vários autores brasileiros que produziram relatos sobre a Amazônia no século XIX, podem ser destacados Gonçalves Dias, Lourenço da Silva Amazonas e Barão de Santa-Anna Nery. Tais autores se imbuem da tentativa de, evocando 
determinadas tradições, configurarem um sentido cultural para o lugar que estavam buscando compreender. Estes autores são, de forma não incomum, recriminados por não dizerem exatamente aquilo que o intérprete gostaria de ouvir ou, então, são forçados a dizerem alguma coisa, tornando-se ou sujeitos precoces da construção da identidade regional. Lourenço da Silva Amazonas (1803-1864), em particular, por vezes foi considerado o precursor do "romance amazônico", dando voz ao regional, por outras, foi apenas mais uma voz etnocêntrica obstinada em submeter os indígenas. Procuraremos com este artigo, conscientes da limitação do horizonte temporal do autor, compreender como Lourenço identificou a região dando protagonismo à revolta indígena de Lamalonga em 1757, situando-a como um dos eventos importantes da formação da nação brasileira.

A ideia de nação aqui utilizada deve muito à noção de comunidade política imaginada como formulada por Benedict Anderson (1989), assim considerada um espaço em criação e atravessado por narrativas que buscam lhe dar um sentido estável, facilmente discernível pela evocação de paisagens ou eventos comuns rapidamente identificados pela memória do leitor. No "olho de sua mente", os leitores de tais narrativas conseguem se perceber enquanto coparticipantes da comunidade, que, longe da estabilidade pretendida, é constantemente disputada, repensada, para não dizer requisitada politicamente. As divergências doutrinais em torno daquilo que é a nação acendem rivalidades ao mesmo tempo em que requerem o desenho claro de um conflito com um outro imaginado. Benedict Anderson lembra que, nos limites imaginados do Estado-nacional, cada um dos leitores do romance (ou do jornal) está convicto de que outros leitores operam leituras semelhantes e participam da mesma narrativa. A cerimônia silenciosa de leitura, que se desenrola na intimidade, reforça os laços de pertencimento à nação ao criar os campos unificados de intercâmbio. A leitura do romance e do jornal fortaleceria “aquela notável segurança da comunidade anônima presente nas nações modernas" (ANDERSON, 1989: 44). Complementarmente, no seu comentário sobre as nações, Stuart Hall sugere que as narrativas da nação "fornecem uma série de estórias, imagens, panoramas, cenários, eventos históricos, símbolos e rituais nacionais que simbolizam ou representam as experiências partilhadas, as perdas, os triunfos e os desastres que dão sentido à nação" (HALL, 2005: 52). Neste caso, a comunidade imaginada diz respeito à partilha destes símbolos por indivíduos anônimos, aos laços de pertencimento ao espaço nacional, à capacidade de manusear narrativas e perceber-se como vinculados a outros indivíduos por meio da identidade política. A 
forma como um vasto coletivo de indivíduos se imaginam enquanto partícipes desta comunidade envolve uma longa disputa narrativa em torno de quais elementos são componentes da nação, quais são seus eventos definidores, como funciona o seu panteão de heróis, etc. É no interior destas questões fundadores que se coloca Lourenço Amazonas em particular, o IHGB, a literatura e a imprensa nacional de forma mais ampla.

No interior da nação ainda mal conhecida pela administração central estão regiões que precisam ser desbravadas para ingressarem definitivamente no corpo físico do Brasil. Tais regiões também possuem as suas narrativas identificadoras que se conectam ao Brasil fornecendo os seus componentes particulares. A região, pela via de sua intelectualidade, busca acoplar-se à nação, afirmando a sua especificidade, seu merecimento, sua herança cultural, o que remete ao conceito geográfico de "região cultural". Este é um aspecto ainda pouco abordado no que diz respeito à formação da Amazônia. $\mathrm{O}$ estudo da Amazônia costuma estar cingido à região geofísica e incide muito pouco sobre os seus elementos culturais unificados na ideia de região, sobretudo na forma como são imaginados pelas elites intelectuais que produzem tais narrativas unificadoras. O geógrafo Armand Fremont fornece uma definição preciosa do espaço regional, apresentando a região como:

um espaço médio, menos extensa do que a nação ou o grande espaço da civilização, mais vasto do que o espaço social de um grupo, e a fortiori de um lugar. Integra lugares vividos e espaços sociais com um mínimo de coerência e de especificidade, que fazem dela um conjunto com uma estrutura própria (a combinação regional), e que a distinguem por certas representações na percepção dos habitantes ou dos estranhos (as imagens regionais) (FREMONT, 1980: 167-8, grifos nossos).

Esta coerência e especificidade, no caso amazônico, devem muito à ação política e intelectual de situar os espaços, detalhar narrativas, eleger ícones facilmente identificáveis e passíveis de serem convertidos numa cultura política, uma vulgata compartilhada. Tendo em mente os conceitos de nação e região, torna-se possível identificar como Lourenço da Silva Amazonas deu um sentido à região como palco político de disputas onde os indígenas, como protagonistas, inscrevem-se na formação histórica do Brasil. Ou, mais precisamente, como Lourenço buscou fornecer mais inteligibilidade para a região e mesmo inscrevê-la na nação em processo de construção. 
Trata-se de indagação que envolve a investigação do pano de fundo contextual disponível aos autores que se dedicaram a escrever sobre o espaço amazônico. No caso de Lourenço Amazonas, seus dois textos mais importantes, os únicos que constam de sua produção bibliográfica, o Diccionario topográfico, histórico e descriptivo da Comarca do Alto Amazonas (1852) e Simá - romance histórico do Alto Amazonas (1857), não apenas buscam um sentido para a região, mas tornam-na, de alguma forma, uma das protagonistas na fundação do Brasil. Ao longo de seu trabalho, Lourenço Amazonas circulou entre povos indígenas e forneceu cuidadosas digressões sobre os seus costumes, entremeadas pelas descrições do ambiente natural no seu Dicionário. Esta obra, impressa em 1852, pouco depois de a comarca do Amazonas ter sido promovida à província, operou uma transformação profunda nas expectativas do autor com relação à nação e à composição da "raça brasileira". Se, na "utensilagem mental" do IHGB, havia fundamental importância na coleta de dados sobre os indígenas, dispondo-os na forma de dicionário, o envolvimento pessoal com a região virá com elementos românticos na obra Simá de 1857. São duas obras que se apresentam em gêneros textuais distintos, mas não antagônicos, podendo-se mesmo dizer que aspiram o mesmo objetivo de buscar a realidade regional e nacional. No Dicionário, a lenta coleta de dados, no romance, a busca por um sentido da nação capaz de identificar no seu interior um povo. A fundação da Amazônia se escora na cuidadosa descrição de lugares, de eventos históricos e de costumes, metaforizado pelo nascimento da menina Simá, a protagonista.

Entrecruzando a história e o romance, Lourenço Amazonas empresta solidez à ideia da inocência inerente ao brasileiro, habitante de belas paisagens, apenas parcialmente fecundado por um Portugal rude, e com ampla possibilidade de construir a civilização original por meio de um cristianismo purificado da influência da metrópole. Mesclam-se aí a filosofia de Rousseau (1712-1778) e seu bom selvagem, as cenas cotidianas dotadas de profunda melancolia de Alphonse de Lamartine (1790-1869), a exaltação da natureza de Álvares de Azevedo (1831-1852), a busca pelo mito indígena de Gonçalves Dias (1823-1864), e mesmo, como o autor elogiará ao longo de algumas de suas divagações em Simá, o romantismo de Joaquim Manuel Macedo (1820-1882). Também um retorno idealizado à natureza e a crítica ao clero e à elite culta se apresentam na obra, marca da influência arcadista, como sugere Marli Furtado (2012). Não é intenção, neste espaço, acessar a biblioteca ou os espaços formativos a que Lourenço Amazonas teve acesso - tarefa não menos interessante - e sim perceber como 
ele utilizou elementos intelectuais, disponíveis em meados do século XIX, para fornecer uma impressão original da Amazônia, convertendo-a numa espécie de metonímia do Brasil.

A construção da Amazônia se apresenta, acompanhando ideia apresentada por Eni Orlandi, a partir de um "discurso fundador", capaz de inaugurar um lugar e dar-lhe um estatuto no seio da história, quer dizer, inscrever uma região no imaginário do "colonizador", um "outro lugar de sentidos estabelecendo uma outra região para o repetível (a memória do dizer)" (ORLANDI, 1993: 15). Em se tratando de um lugar distante, mesmo pouco perceptível para o imaginário da elite intelectual do Império, Lourenço precisa evocar memórias que possam ser facilmente acionadas e assim fixar um "lugar de sentidos". Para realizar tal tarefa, Lourenço empresta contornos europeus ao seu protagonista indígena, que atende pelo nome de Marcos. Este procura por uma região tranquila onde pudesse, purgado do mal de que foi vítima, iniciar uma nova fazenda com a sua neta mestiça, renascendo com o nome de "Severo". Nesta fundação de um lugar, onde se cruzam os elementos da nação com os elementos regionais, o indígena é apresentado como inerentemente ingênuo, sendo essa ingenuidade tanto mais favorável para o benefício da fé cristã (aquela na qual, segundo Caminha, "em tudo se plantando dá”). Ainda, contudo, que na linhagem dos escritos jesuíticos, o índio seja naturalmente inclinado ao cristianismo, não reúne condições para dizer e, independentemente de qualquer contágio europeu, não ingressa na história. No romance de Lourenço Amazonas, a nação brasileira surge do pecado português contra o índio, mesmo pecado cometido por Régis, um regatão português, contra a índia Delfina, filha de Marcos/Severo, espécie de índio cavalheiro, da qual resultou a mestiça Simá, não só uma perfeita e pura cristã, mas também uma brasileira. A atitude cristã de Lourenço Amazonas vem acompanhada de forte desconfiança com relação ao jesuíta, que estaria intoxicado pela postura colonialista, pela sede de poder e, subsequentemente, por uma visão deformada do cristianismo. A nossa hipótese é que, revolvido no seio de elementos literários de época como o romantismo, a idealização da natureza e do indígena, Lourenço busca dar um sentido para a Amazônia e configurá-la como um destes lugares fundadores da nação.

Esta hipótese será desenvolvida através de quatro seções no corpo deste artigo, uma primeira destinada a identificar o pano de fundo disponível a Lourenço Amazonas no IHGB, seguindo a linha de história das ideias sugerida no início do texto, da utensilagem mental do autor. Uma segunda seção será destinada para ler mais 
cuidadosamente os elementos de seu Dicionário, buscando ver como reúne elementos históricos e etnográficos que permitem gerar uma leitura da região e torná-la o palco de um romance histórico. Por fim, a busca, numa análise de narrativa que tem como núcleo os conceitos de nação e região, a tentativa de gerar uma compreensão de como estes elementos prévios se fundem na composição da obra e o que o autor busca dizer com ela, forjando um lugar para a Amazônia dentro do Brasil.

\section{Lourenço Amazonas e o IHGB}

$\mathrm{Na}$ condição de pesquisador do Instituto Histórico e Geográfico Brasileiro e Capitão-Tenente da Armada, o baiano Lourenço da Silva Araújo e Amazonas compôs o Diccionario topográfico, histórico e descriptivo da Comarca do Alto Amazonas (1852) e Simá - Romance histórico do Alto-Amazonas (1857). Em expedição pela região amazônica ao menos desde 1848 (JOBIM, 1943), coletou inúmeros dados sobre fauna e flora, acessou documentos sobre a formação histórica da região e entrou em contato com várias comunidades indígenas, sobretudo no Rio Negro. Da mesma forma que os diversos viajantes vindos do estrangeiro ou de outras regiões do país, estas duas obras realizaram uma tentativa de dar inteligibilidade para a região, inscrevendo-a numa nação em processo de crescentes transformações políticas: trata-se do século da expansão napoleônica e do Congresso de Viena (1815), com a consequente independência brasileira e várias revoltas contra a autoridade regencial. Século de convulsão política em que os reflexos da Revolução Francesa e o principal teórico dos revolucionários, Jean Jacques Rousseau, se tornaram elementos fundamentais para pensar as realidades nacionais.

O IHGB, fundado em 1838, inscreveu-se no interior de um conjunto de preocupações em dar um contorno para o Estado brasileiro, articulando as várias regiões do Brasil e definindo um sentido para a nação em processo de consolidação. Através dos saberes gerados pelo IHGB, deveria ser possível delinear uma consciência nacional e integrar os vários e dispersos brasileiros. Estes saberes implicavam o desbravamento dos sertões e, posteriormente, sua fecundação por um intelecto letrado "como um processo hierárquico de cima para baixo, nos moldes do iluminismo europeu" (GUIMARÃES, 1988: 6). Como sustenta Guimarães, a identidade política forjada nos 
primeiros anos do IHGB não era tão definida pelo sentimento antilusitano como nos periódicos que sucederam o processo de independência política entre 1820 e 1822 (NEVES, 2003), mas aparece como continuadora da tradição portuguesa, aglutinada em torno da figura de D. Pedro II: "nação, Estado e Coroa aparecem enquanto uma unidade no interior da discussão historiográfica relativa ao problema nacional" (GUIMARÃES, 1988: 6). Parte significativa dos fundadores do IHGB era nascida em Portugal, motivo pelo qual se viu afastada do forte antilusitanismo da imprensa produzida na luta pela independência, a começar pelo Cônego Januário da Cunha, autor do Revérbero Constitucional Fluminense em 1821 e um dos fundadores do IHGB. A partir de 1850, com intelectuais nascidos no Brasil, caso de Lourenço Amazonas, Joaquim Manuel Macedo e Gonçalves Magalhães, essa tradição será gradualmente transformada, a partir da intensificação de um projeto político centralizador que começa a incorporar mais ativamente elementos nativos. $\mathrm{O}$ intelectual, qualquer que seja, está profundamente vinculado ao seu dever diante do Estado. Como constatou Raimundo Faoro, o Estado português se projetou sobre qualquer coisa da população dispersa pelo território brasileiro, mais do que a fecundando, sufocando (FAORO, 2012). Trata-se de um traço histórico do patrimonialismo no Brasil. Pode-se falar, portanto, que o IHGB ajuda a instrumentalizar, como órgão de Estado, a tentativa de fornecer um corpo conexo à nação em direção a um dado progresso histórico. Nisso, estão presentes a ideia de que a história e a geografia auxiliam na compreensão dos aspectos singulares da nação. Os índios, sendo percebidos como exteriores à história, deveriam ser estudados não pela historiografia, mas pela etnografia, e incorporados na civilização brasileira por meio do trabalho.

Para a constituição da história do IHGB, a Independência de 1822 serve como data fundadora (MALEVAL, 2019). Estando aí fundado o Estado, constata-se a necessidade de recolher documentos que permitam aos coevos compreender o sentido interno da evolução da nação. Em 1849, D. Pedro II requisitou aos membros do IHGB que buscassem mais ativamente a escrita da história nacional ao invés da pura coleta documental (MALEVAL, 2019). Como lembra Maleval, os textos produzidos no âmbito do IHGB mencionam o "tribunal da posteridade", buscando se afastar da avaliação política de eventos atuais ao mesmo tempo em que se distanciar do "tumulto" da imprensa periódica, firmando sua posição de intelectuais esclarecidos. Aos poucos, entre estes intelectuais esclarecidos se solidifica a ideia de que a conclusão da nação será resultado da unidade racial nos moldes europeus (BAULER e KEIM, 2011). 
Miscigenação, branqueamento e imigração europeia se apresentam constantemente como tópicos ordenadores da visão destes intelectuais.

Januário da Cunha Barbosa argumentou, em seu artigo sobre "a melhor maneira de colonizar os índios", em 1840, sobre a importância do entendimento da língua dos indígenas para o êxito da empreitada de catequização e sua integração na sociedade brasileira. Na história geral de Varnhagen, de 1854, não caberia ao indígena um papel na história, mas somente na etnografia, dada a sua "incapacidade" de se agregar em sociedades sedentárias (BAULER e KEIM, 2011). Mais tarde, em 1860, Gonçalves de Magalhães rebate Varnhagen e se dirige aos colonizadores da América Latina como "bárbaros", ao fazer referência à destruição causada contra os impérios inca e asteca, que resultaram na degeneração dos povos indígenas: “documentos incontestáveis de uma civilização de caráter antigo e original, que denuncia gerações sucessivas e séculos para ter chegado a esse ponto e esplendor" (MAGALHÃES, 1860: 11). No interior dessa elite intelectual e ao mesmo tempo burocrática, a herança lusitana pende de um lado para o outro, ao mesmo tempo em que o negro é completamente apagado: a expectativa do seu apagamento se dá pelo branqueamento. Desde os escritos da imprensa na independência, evidencia-se entre os círculos letrados, a começar por Hipólito da Costa e José Bonifácio, que a escravidão é um estigma que precisa ser superado, e o negro o emblema desse estigma que sufoca a nação em direção à servidão.

Partindo da preocupação com a integração do Brasil, composto pela sua terra e gente, houve no IHGB uma maioria de estudos voltados para questões indígenas e regionais. No caso da região que nos diz respeito, a Amazônia, a preocupação política com este espaço pode ser entrevista pelo aumento nas menções nos Anais do Parlamento e na imprensa nacional. Nos Annaes do Parlamento Brasileiro, a Amazônia começou a aparecer sobretudo a partir das intervenções do deputado Bento Tenreiro Aranha. Ela era apresentada então como uma região orientada pelo fluxo do grande rio Amazonas e ligada inevitavelmente ao Brasil, num sentido geográfico estável patente na expressão "ilha Brasil”. A transformação do Amazonas numa província autônoma em 1850 deu força para o tópico Amazônia na imprensa e no Parlamento. Segundo o censo geral de 1872, a população do Amazonas contava 57.610 almas, sendo que mais da metade (29.334) estava localizada em Manaus. Ainda não se experimentaram, nesse período, os eventos econômicos definidores da expansão da borracha (a partir de 1879), quando a população se multiplicou muito rapidamente, atraindo migrantes de outras regiões e países e, fato de não menor importância, assistindo a um número cada vez 
maior de periódicos impressos e a multiplicação de "escritores públicos" ou jornalistas. Temos ainda uma vila acanhada, depois do caos administrativo gerado pela Revolta da Cabanagem (1835-1840), que resultou na interiorização maciça dos revoltosos. Também a navegação internacional do rio Amazonas ainda é objeto de ativa discussão no Parlamento, sendo autorizada somente em 1866. Com modestíssima arrecadação tributária e severas restrições para o financiamento do ensino público, uma população dispersa pelo vasto território e atividades extrativas pouco conectadas com o comércio nacional, pode-se vislumbrar o estado de acanhamento da vila de Manaus descrita pelos viajantes, desde brasileiros como Gonçalves Dias entre 1861 e 1862 até estrangeiros como Louis e Elizabeth Agassiz entre 1865 e 1866. Em 14 de fevereiro de 1850, o ainda deputado Bento Aranha argumentou, no Parlamento, a importância da civilização dos indígenas por meio da catequese, ao invés das violências que se vinham praticando, para que se pudesse garantir a posse efetiva da região (Annaes do Parlamento, 14 de fevereiro de 1850). Gradualmente, a ideia de vencer o enorme vazio demográfico vai tornar a discussão sobre a instalação de colônias de estrangeiros frequente, somada à "civilização" dos indígenas e sua adaptação ao trabalho sedentário. A ideia de integração da Amazônia no Brasil começou a aparecer também em jornais, sendo exemplo disso em 12 de novembro de 1853, O Liberal Pernambucano (PE), que circulou entre 1852 a 1858, sugerindo a integração de rotas fluviais entre a Bacia do Prata e a Bacia da região amazônica. Está colocada também na imprensa a ideia de que, na formação do Brasil, o território está dado e se apresenta de forma natural. Bastaria somente que o Império o protegesse por meio de rotas de navegação fluvial. Ao mesmo tempo, a navegação e o subsequente povoamento das zonas fronteiriças conteriam a sanha invasora de outras nações. O Observador (MA), que circulou entre 1847 a 1861, em Correspondência do Interior vinda de Manaus em 13 de janeiro de 1858, referiu-se às eleições provinciais na Amazônia, quando a autoridade velou sempre na manutenção da ordem e tranquilidade pública: “À boa índole do povo da Amazônia deve-se o perfeito sossego que reinou durante os quatro dias do pleito eleitoral". Assim, a região ia se tornando parte da nação por meio da política e da navegação. Também no Maranhão, no Jornal de Timon: Publicação Mensal (MA), que circulou entre 1853 a 1858, contendo "Apontamentos, notícias e observações para servirem à História do Maranhão", na sua edição 6 de 1853, a Amazônia apareceu como o último reduto em que se escondiam os indígenas ariscos à civilização. Desta vez, fala-se nos desertos da 
Amazônia, ainda impermeáveis à modernização, questão com a qual se baterá toda a produção jornalística e literária regional.

Tanto no IHGB quanto no "tumulto" da imprensa, evidencia-se a dificuldade de encontrar a unidade do elemento brasileiro. Dificuldade que consolida e amplia as primeiras indagações de intelectuais pioneiros como Hipólito da Costa e José Bonifácio sobre a constituição do Brasil, atravessada como deveria ser pela sua geografia, história e raça. A preocupação de Hipólito da Costa com o delineamento claro de um elemento brasileiro, herdada pela imprensa nacional, era tamanha que resultou na construção de um vocábulo específico para o indivíduo civilizado que deitou raízes no Brasil: "braziliense". Afinal de contas, 30 anos depois da independência do Brasil com relação a Portugal, quem era esse brasileiro?

\section{O Dicionário de Lourenço Amazonas}

A criação da Província do Amazonas é resultado da lei imperial n. 582 de 5 de setembro de 1850. Lourenço Amazonas, ao fazer a composição do Dicionário, destaca que quando a Província foi criada ele já havia redigido boa parte do texto. Os elementos do Dicionário espelham aquilo que se poderia chamar de uma geração romântica do IHGB, mais desconfiada das benesses da colonização e preocupada com discernir o brasileiro do português. Dado sentimento antilusitano afirma-se pela convicção de que o colonizador emprestou ao colonizado os maus hábitos, transmitiu-lhe o aspecto degenerado da civilização purgando-lhe de suas virtudes. Lourenço Amazonas possui assim preocupações, como membro do IHGB, etnográficas e catalogadoras. Por outro lado, com um Rousseau já abrasileirado, percebe a civilização como o resultado da degradação da simplicidade natural do homem, degradação encarnada pelos jesuítas pervertidos e comerciantes portugueses parasitários. A resistência a esse processo de queda está no próprio indígena. Ao descrever eventos fundadores da região amazônica, Lourenço Amazonas se detém na Revolta de Lamalonga (1757) que serve de inspiração para o seu romance Simá. Além dos constantes descimentos dos portugueses na região, elaborados a partir de complexas redes de interações com principais indígenas, contando com a mediação de missionários, o alto Rio Negro se viu acometido por epidemias de varíola e sarampo a partir anos 1740 que dizimaram várias comunidades 
indígenas, inclusive algumas delas com pouco ou nenhum contato com colonizadores, por meio dos tecidos de algodão. No contexto de uma rebeldia cada vez maior com relação aos descimentos realizados pelos portugueses, e depois de frustradas tentativas de negociação levadas a cabo pelo governador do Estado do Grão-Pará e Maranhão, Francisco Xavier de Mendonça Furtado, em 1757 explodiu um conflito em Lamalonga, próximo de Barcelos. O lugar, como lembra Patrícia Sampaio,

[...] foi palco de uma revolta de índios, sob o comando de seu Principal Domingos, aparentemente contrariado com a intervenção do missionário que o instava a abandonar uma de suas mulheres. Domingos aliou-se aos Principais João Damasceno, Ambrósio e Manoel e, juntos, atacaram com violência a casa do missionário, depois, a igreja e, por fim, colocaram fogo na povoação. Entre junho e setembro, de acordo com o ouvidor Francisco Ribeiro de Sampaio, ampliaram de forma significativa seu rol de aliados, entre eles estavam Manacaçari, Mabé (Principal de Poiares), Canaruana e Banacari (SAMPAIO, 2011: 11).

A rebelião, que marcou a insatisfação dos indígenas contra a intervenção dos missionários em sua teia de costumes, teve como foco a destruição das igrejas e símbolos religiosos, bem como o assassinato do padre carmelita. Tendo em mãos estes elementos históricos, Lourenço Amazonas buscou conferir densidade psicológica e moral à revolta indígena, apresentando assim o índio como um agente ativo da história e senhor de suas decisões.

O Dicionário topográfico é também uma espécie de documento no qual constam reivindicações políticas do Amazonas, a busca pelo seu delineamento histórico específico, seu estatuto e datas fundacionais. Comungando a percepção iluminista acerca do comércio, Lourenço Amazonas vê o intercâmbio entre os povos como um elemento fundamental de civilização que permite também o alcance de maior conhecimento. Estas trocas estariam sendo dificultadas pela província do Pará, um resquício do autoritarismo português que esmagava o Amazonas. Assim, o comércio na região amazônica teria se pervertido, transformado, ao invés de em veículo das "luzes", em "alavanca de imoralidade":

O comércio sendo em qualquer outra parte, pelas comunicações e relações que estabelece, um veículo de conhecimento e ilustração, e não raras vezes, 
como honrosos monumentos o atestam, o mais pronto e eficaz meio de grandes e patrióticas empresas em vantagem da humanidade e civilização, no interior do Pará, na Comarca do Alto Amazonas é a alavanca mais possante de imoralidade (AMAZONAS, 1852: 42, grifos nossos).

Os problemas da Assembleia Provincial do Pará estão na sua pretensão monopolista, seu autoritarismo e cegueira com relação às reivindicações da comarca do Amazonas (AMAZONAS, 1852: 43). Vão se delineando, ao longo dos vocábulos descritos no Dicionário, os elementos que serão aprofundados no romance. Dentre outras preocupações características dos historiadores do IHGB, demonstradas por Lourenço Amazonas, estão a questão das fronteiras e da defesa da soberania nacional. A partir de uma ambiguidade, já que escreve na instituição patrocinada pelo Imperador D. Pedro II, ao mesmo tempo em que vê com desconfiança a herança colonizatória, limitase a considerações de ordem prescritiva, nos moldes formais dos poderes e nas Leis (com maiúscula) inspirados por Montesquieu:

Ressalta pois de tudo isto a necessidade de um Governo, cuja ação não só se faça sentir beneficamente no interior, mantendo a observância das Leis, efetuando as disposições do Governo Supremo, como também, enérgica e vigorosa nas Fronteiras, contenha em respeito o estrangeiro. E o país urge instantaneamente: parte integrante do Império, tem direito como qualquer outra à igualdade que a Lei consagra: insultado e invadido pelo estrangeiro, e todavia exposto a sê-lo sempre que assim lhe convenha, deve-lhe o Governo proteção, que os brios e dignidade lhe sustentem. Tal proteção só pode proporcionar-lhe um Governo, que também segundo a Legislação só pode proporcionar-lhe o predicamento da Província (AMAZONAS, 1852: 87, grifos nossos).

"Interior", "fronteiras" e "parte integrante" remetem ao vocabulário utilizado constantemente pelos intelectuais vinculados ao IHGB - evidentemente, não só a eles. A tão mencionada "integração" da Amazônia ao Brasil só poderia se dar pela educação do indígena, até então maltratado pelos portugueses, fossem estes comerciantes ou jesuítas. Os poderes políticos portugueses, do qual os brasileiros são herdeiros, são tratados de passagem: a província do Pará é autoritária, mas ao que tudo indica o Poder Central, encarnado por D. Pedro II, tem capacidade de resolver situações conflitantes já 
que se apresenta no formato moderno de poder moderador, segundo a doutrina de Benjamin Constant. Os europeus, de modo geral, maltrataram os indígenas e sua presença se tornou ruim. Sobre estes maus tratos aos indígenas, Lourenço Amazonas diz:

Lástima, que os europeus pela descoberta da América só tenham querido estimar em seus indígenas a aptidão para servir, considerando-os mais como brutos que como escravos; chegando o abandono a ponto deles, que na Europa não duvidavam partilhar a humanidade com os negros da África, seus vizinhos, recusassem fazê-lo na América com seus indígenas, a ser precisa a Bula de Paulo II, de 10 de junho de 1537, para reabilitá-los na ordem em que os colocara o Criador (AMAZONAS, 1852: 143).

A hierarquia racial, como em geral entre os literatos brasileiros do século XIX, apresenta o negro num degrau inferior, hostil à civilização, já que "inerentemente" escravo, enquanto o indígena um material maleável, passível de receber tratamento civilizatório. Nesse sentido, seria necessária a instrução, já que os mais ilustrados devem aprender e apreciar melhor as características do país e assim "aplaudirão a sua feliz origem" (AMAZONAS, 1852: 177, grifos nossos). Apresentam-se, de forma inicialmente ambígua, os jesuítas, em alguns cantos do Brasil "profícuos", mas em outros, caso específico da Amazônia, protagonistas de "odiosos feitos". Estes odiosos feitos jesuíticos vão se traduzir também no romance, quando eles parecem ser intermediários civilizatórios mais corrompidos do que os próprios comerciantes:

A opinião ainda não resolveu definitivamente o conceito em que devam ser tidos os Jesuítas. Quanto ao Brasil, pode ser, e ingratidão seria negar, que em algumas províncias (principalmente do centro) fossem profícuos; porém não assim no Pará, e principalmente no Alto-Amazonas, onde por todo o vestígio de sua presença deixaram as atuais freguesias de Araretama e Itacoatiara; e na História bem odiosos feitos, como a invasão do Solimões no princípio do século passado, a imediata agressão de suas povoações em 1709 e as hostilidades no Solimões, Negro e Branco de 1755 e 1759 (AMAZONAS, 1852: 249, grifos nossos). 
Para não restar dúvida sobre este intermediário inconveniente, Lourenço Amazonas se refere às pretensões dos jesuítas no interior do Reino Português, ambiciosos em deterem a alma dos indígenas colocando-os para trabalhar servilmente. No seio dessa perversão, apenas contribuíram para, pela sua vontade de poder, lubrificar as engrenagens da escravidão, já que "por seu ulterior e pérfido comportamento se não tivessem desmascarado, deixando ver todo o alcance de suas ambiciosas pretensões. Desgraçadamente para o indígena tudo foi escravidão" (AMAZONAS, 1852: 231). Estão lançadas assim as sementes do "romance histórico no Alto Amazonas", que tem nos principais indígenas os motores da Revolta de Lamalonga.

\section{Elementos do romance Simá}

Antes de qualquer coisa, importa dizer que Lourenço Amazonas não utiliza o vocábulo Amazônia: o teatro da revolta indígena descrita é o Amazonas e o Amazonas é uma região que exclui o Grão-Pará. A Amazônia é uma lenta construção, como bem lembrado pela Neide Gondim (1994), pairando no imaginário estrangeiro entre o Éden e o Inferno, mas sobretudo imaginada por intelectuais viajantes, cientistas ou elites políticas nativas que, na impossibilidade de ver com realismo o imenso e incognoscível território, desenham-no com forte coloração onírica. No contexto de busca pela nação, Lourenço Amazonas deixa o seu posto de historiador do IHGB e se torna um romancista. É no romance que ele pode, dando materialidade à imaginação, trabalhar a sua ideia sobre a pureza brasileira. Pureza nascida, contraditoriamente, da violência da civilização contra a inocência. Ao final do enredo do romance a tragédia, como lembra Marli Furtado, "não acende nenhuma luz de esperança, afinal, o domínio português demarcou sua posse, incrustou seus símbolos, estabeleceu fronteiras e não teve pejo nem pena, nem respeito a não ser por sua própria ideologia colonialista" (FURTADO, 2012: 3). A protagonista da narrativa, contudo, não é propriamente um indígena, mas, o que é significativo, chamada de uma "mameluca" de nome Simá, expressão que exprime mais a junção étnica do que, evidentemente, evoca no contexto qualquer efeito pejorativo. No cenário do seu crescimento, educada por missionários carmelitas, bondosos se em comparação com os corrompidos jesuítas, Lourenço Amazonas fermenta um profundo desgosto com relação à presença parasitária dos portugueses. Simá é a neta de Marcos/Severo, fruto do estupro de sua mãe Delfina pelo comerciante 
português Régis, tornado metáfora da violência portuguesa contra o indígena. O suporte da narrativa é o épico grego: tanto quanto Helena de Troia, a interrupção do casamento de Simá com o nativo Domingos fez eclodir a revolta dos indígenas. Assim, Simá é apresentada como a "Helena do Rio Negro" (AMAZONAS, 1857: 7). Alguns julgamentos sobre a obra de Lourenço Amazonas desconfiam de sua fatura literária: a obra traria descrições excessivamente longas e pouco realistas, e seus personagens se confundiriam o tempo inteiro com a voz do autor. Para Dantom Jobim, por exemplo, "o seu romance Simá, tomando por cenário o Rio Negro, não tem centelha, e deixa muito a desejar, não obstante os quadros descritivos, que o escritor se compraz em colorir" (JOBIM, 1934: 18). Para Marli Furtado, discutindo o porquê de, lançado em 1857, mesmo ano de $O$ Guarani, Simá não ser lembrado como romance indianista de alcance nacional, recorda que Lourenço Amazonas não circula entre os meios de literatos da época, apresenta-se como figura periférica, sua produção é pouco volumosa e a leitura é difícil e confusa mesmo para os padrões da época. Ao mesmo tempo, há longos parágrafos e as falas dos personagens várias vezes se embaraçam num tom monocórdio de cavalheiro europeu. Até mesmo o indígena Marcos/Severo fala como um lorde inglês. Pouco da linguagem coloquial dos indígenas é empregado nos diálogos. Para Amilton Queiroz, em outra visão sobre Simá, a obra é uma ficção colonialista destinada a não somente se apoderar dos “corpos indígenas", submetendo-os ao jugo ocidental, mas também "produzir um discurso que visa a homogeneizar as mais diferentes tribos indígenas amazônicas” (2009: 27).

No que concerne a este último ponto, para além da obviedade de que a visão de Lourenço Amazonas representa aspectos etnocêntricos em seu confronto com as comunidades indígenas, importa pensar como ele buscou dar um passo além da tradição que funciona como suporte - a própria água na qual nada o peixe - tentando emprestar dignidade ao protagonismo do indígena na composição do Brasil. Num círculo hermenêutico, Lourenço Amazonas se inscreve numa tradição de viajantes e etnógrafos, caminha entre o Éden e o Inferno, ao mesmo tempo em que descreve e incorpora nela o índio, recolocando-o como ator principal. Um ouvido cuidadoso para a fonte primária, como sugerimos ao início deste artigo, é antes de tudo um projeto que implica despir-se da tentação acusatória que, pela via do maniqueísmo, impede que se explorem com profundidade as interconexões entre a cultura letrada daquele que narra e a cultura oral daquele que ingressa na narrativa. 
Contrariamente à ortodoxia da visão colonizador/colonizado, o olhar condenatório de Lourenço Amazonas pelo choque civilizatório é evidenciado ad nauseam, mas sobretudo estampado nos vilões Régis e Loiola, este último amigo de Régis, carregando, não por acaso, o homônimo do fundador da Ordem dos Jesuítas. Ao final da narrativa de Simá, numa Assembleia de indígenas que decidirá o futuro dos índios Manaus, apresentam-se tanto elementos pacificadores quanto elementos mais agressivos, que decidem iniciar uma guerra contra a presença dos portugueses a partir da ambiguidade gerada pela luta revolucionária (a lembrança da Assembleia francesa é inevitável). Na indistinção da guerra, a heroína Simá é trucidada pelo fogo ao lado de seu pai e algoz. Régis, o pai, é também o pai português do brasileiro, diante do qual importa se emancipar.

O conhecimento etnográfico e mesmo de língua indígena que o autor detém estão exibidos no Dicionário. O romance é um recorte explícito, com objetivo ficcional, que tem como personagens índios Manaus que habitam o Rio Negro seu pano de fundo. Neste, o estouro da rebelião está implícito na própria violência da colonização malconduzida. Ao descrever os eventos da revolta de Lamalonga, Lourenço Amazonas evoca a Ilíada e a Eneida e insinua a existência de um Menelau entre os Manaus, o índio Domingos, tomado de fúria pelo sequestro de sua amada (AMAZONAS, 2011: 14). O autor busca a sua autoridade na Antiguidade clássica, e escora a pretensão de validade histórica na composição da obra no estudo documental do Dicionário para o qual, na condição de "onisciente intruso", remete o seu leitor. Os contornos das falas são épicos e aparecem sempre adornados pela volúpia textual do romantismo. Nos primeiros diálogos, o regatão Régis busca extrair vantagens de Marcos/Severo que, longe de um "tapuio ordinário" (2011: 28) está entregue à civilização e ao trabalho. Tapuio, explica o autor em nota de rodapé, é um "servo", expressão não extensiva aos indígenas livres. O que importa talvez não seja tanto a visão que Marcos/Severo tem dos outros indígenas quanto o acolhimento que o autor oferece para ele na civilização brasileira, o ponto de partida de sua fala, seu contexto. Da violência física e simbólica do regatão Régis contra Marcos/Severo e sua família surge o Brasil interior, a Amazônia, que tem vida própria, e tendo vida própria, rebela-se contra a injustiça de que é vítima.

Numa cena emblemática, o comerciante Régis e o indígena fazendeiro Marcos/Severo discutem a civilização. Régis defende o campo coberto de plantações e Marcos/Severo defende a vida em conformidade com a natureza, quer dizer, os pequenos bosques cultivados (AMAZONAS, 2011: 29). Marcos/Severo é a voz que 
Lourenço Amazonas produziu para contradizer a civilização propagandeada por Régis, do comerciante buscando o lucro. Um recurso possível dessa argumentação é o Discurso sobre a desigualdade (1754) de Rousseau, extensa meditação sobre "a igualdade que a natureza pôs entre os homens e sobre a desigualdade que eles instituíram", sendo Rousseau mencionado três vezes ao longo da narrativa de Simá. Na sua visão sobre a civilização, Marcos/Severo diz, ironicamente (a ironia é uma figura de linguagem onipresente entre os personagens abrasileirados):

Que felicidade para vós a de uma sociedade de senhores e escravos! Mas em que vós sois os senhores! Que lisonjeira perspectiva a do indígena, civilizado a vosso modo! Careceis uma serva para vossa casa? Arrebatais uma mulher a seu marido, uma filha a seus pais. Que bela civilização? E o modo de convidar a ela? Levais a vossa Bandeira a um rio: esta cerca uma maloca: bate-se com quem resiste, atira sobre quem foge, e conduz escravos a quem não pôde conseguir, fugir ou morrer: destes (escravos) apurada a escolha segundo vossas necessidades, o refugo entregais a um missionário para dispor cidadãos ao Estado! Que felicidade para o indígena! Que outro não sabeis vós tornar um poder selvagem! (2011: 31).

Finalizada a conversa, o comerciante português coloca ópio no vinho, embriaga Marcos/Severo e sua filha Delfina e a estupra. Marcos/Severo se vê "desonrado", confundido com "tapuias ordinários", mas a origem disso é a "bela menina mameluca" (2011: 47), símbolo de "angélica bondade" (2011: 49). A assunção de um cristianismo ordenador, diante do qual o selvagem está mais próximo da identidade divina, é assegurado pelo slogan: "Tudo é bom como saiu das mãos do Criador. Tudo degenera entre as dos homens" (2011: 53). A opção por Rousseau parece evidente. Amazonas tanto nega a civilização e a corrupção nela inerente quanto enxerga no índio a índole pura do selvagem.

A descrição exaustiva das paisagens, que por vezes parecem muito mais bosques franceses do que as tórridas florestas amazônicas, parece extraída de Lamartine, cujas Primeiras Meditações Poéticas de 1820 inspiraram também Alvares de Azevedo. A melancolia de Lamartine se funde ao edenismo descrito pela Neide Gondim (1994):

Como descrever a doce melancolia, que em êxtase parece suspender a sensação de si mesmo a um luar sob o céu, tão feliz, como o de Manaus, 
impressionado da pureza e diafaneidade da atmosfera, qual o assomo de uma aurora boreal, em cuja claridade se desenham as árvores com fantásticas configurações; do noturno silêncio, interrompido apenas pelo incessante longínquo som da cachoeira, que o vento em suas ondulações faz parecer ora mais, ora menos distante... (AMAZONAS, 2011: 56). Desculpados pois, como permitimos nos pretender da obrigação de uma fiel descrição da paisagem - Éden - que nós honramos ponderar ao leitor, seja-nos permitido prosseguir sem mais cerimônia (AMAZONAS, 2011: 57, grifo nosso).

Mais tarde, o comerciante Régis conversou longamente com seu colega Loiola, figura ainda mais corrompida, agora não somente pelo comércio viciado como também pelo hedonismo. Lourenço usa o diálogo entre os dois para dar algumas opiniões sobre a "moderna literatura", o "progresso" que corre a passos agigantados, mencionando Fenelon, Bossuet, Molière e Voltaire, ao mesmo tempo em que tentando imaginar o iluminismo como pano de fundo cultural da Revolta da Lamalonga (2011: 69). Ainda os dois portugueses conversam sobre as tradições nacionais e a própria ideia de nação, entre a necessária herança cultural dos povos, temperada com elementos populares geralmente pouco racionais, e a construção letrada dos iluministas, disposta a construir um "novo homem" (2011: 72). A ideia de que a ilustração acabará com a ignorância é recebida com cautela por um certo sentimento conservador que sugere que, na composição da nação, os seus povos, território, raça ou história específicas contém elementos imanentes, como se demonstra no folclore ou na literatura popular. Diante da sugestão iluminista de que os elementos irracionais da cultura devem ser suprimidos em favor da razão e do progresso, Lourenço Amazonas pondera, no diálogo entre Régis e Loiola, que a supressão das crenças dará lugar à "incredulidade", vista como um "salto de olhos fechados":

Fora bom que o desabuso da impostura eles fizessem resultar da ilustração: mas para isso seja-me permitido duvidar, tanto da capacidade como da intenção de nossos jovens demagogos, os quais de certo se não houveram de hoje entre nós de outra maneira, do que soem fazer em todo o tempo e em toda a parte. Falsas ou verdadeiras, eles atacarão de chofre nossas crenças, e com elas quanto lhes é inerente, atirando-nos em uma situação tão falsa, na qual haverá apenas de real o seu proveito em resultado de sua astúcia e malignidade. Pretensão excessiva de si mesmos, impostura revoltante, 
palavreado oco do sentido, desdém, reprovação e escárnio de tudo, que deles não provêm, eis suas habilitações. Perplexidade, desânimo, prostração, e quanto faz o horroroso cortejo da incredulidade, tanto mais fatal, quanto a ela se passe de um salto a olhos fechados, continuando-se sempre a jazer na antiga ignorância; eis a partilha do povo que lhes der ouvidos. E alardeai lá de vossa brava rapaziada (2011: 72, grifos nossos).

Através desta discussão sobre a nação, Lourenço Amazonas prepara o terreno para inserir os indígenas no receituário da composição da consciência nacional, ainda que enquanto falantes de português erudito inacessível até mesmo para os alfabetizados da época.

\section{0 ingresso do indígena na história}

Os elementos de ebulição social que configuram o pano de fundo da revolta culminam numa Assembleia indígena que, a exemplo da Assembleia francesa, precederá a exaltação coletiva. Reunidos em Assembleia, ou Conselho dos Principais, os indígenas discutem os aspectos perversos da colonização e sua condição de escravos diante dos usurpadores portugueses. Lourenço Amazonas usa o personagem do "velho Jacumá” para criticar a postura do colonizador. Junto com o jovem Domingos, pretendente de Simá, eles conversam sobre a necessidade de uma revolução. O velho Jacumá, peremptório, guarda a posição de Lourenço Amazonas sobre o assunto:

que habilitação pode ter adquirido para as distinções sociais, o indivíduo criado na escravidão, e adrede nela embrutecido? Ide no meio dessa sociedade, a que se nos diz hoje pertencermos fraternalmente: o que observareis? O português na sala, e o indígena na cozinha! O português instruído, e o indígena ignorante! O português rico, e o indígena pobre! E em resumo o azorrague do português, e as costas do indígena! Sempre a indignação no coração, e o insulto na boca do português, e o sentimento no coração, e as lágrimas nos olhos do indígena!... oh que liberdade, que franquezas, que concessões!!! (AMAZONAS, 2011: 82-3). 
O diálogo opõe a liberdade, ao modo indígena, à escravidão, ao modo europeu, tendo a liberdade perdido espaço no mundo indígena desde a colonização. Romantismo, nativismo e revolução se fundem para criar a Amazônia. Lourenço Amazonas traça a cronologia da luta revolucionária no Brasil buscando demonstrar que há uma seiva revolucionária correndo no país, em seus “ancestrais", sendo a Revolta de Lamalonga um dos eventos antecipadores da independência. A revolta ocorre no mesmo ano da criação do Diretório dos índios em 1757. Momento em que, novamente, a Coroa portuguesa afirmou a liberdade dos indígenas para torná-los vassalos da monarquia, os jesuítas foram expulsos e aldeamentos de caráter secular criados. O indígena civilizado, portanto, era o que aceitava a catequese e a redenção por meio do trabalho. A direção das aldeias, retirados os jesuítas, passou aos colonos, sejam civis ou militares, chamados de "diretores de índios". A ação dos índios em revolta, sendo alguns elementos mais "aleivosos" do que outros e portanto dispostos a cometerem injustiças (similarmente à Revolução francesa), inscreve-se na História do Brasil como um evento fundador, de revolta autóctone contra a colonização mal conduzida, da mesma forma que, como lembra Lourenço, a revolta dos mascates ou a revolução pernambucana. O autor assim descreve a ação da "nação indígena", sendo significativo que a chame de nação ao invés de um amontoado de tribos:

Somos levados a crer surpreendido o nosso leitor, não só pelo afinco e denodo, com que uma nação indígena (Manaus) nas margens do rio Negro, a braços ainda com o selvagismo e a civilização, já pugnava pela independência como por ouvir o nome - jesuíta - compreendido naquela questão. Quanto a primeira, não achamos muito de que maravilhar, quando lendo a História do nosso país, nos resignamos a crer que uma inspiração divina de certo tempo até o rompimento de 1822. A época, a que nos referimos, quanto aos Manaus, pouco difere daquela, em que o primeiro brado pela independência foi levantado nas margens do Beberibe, na questão, a que se deu o nome - dos Mascates - em prol dos quais se pretendeu monopolizar um país, que os brasileiros, sem outro recurso e assistência, mais do que seus próprios esforços haviam disputado a Holanda para sua pátria: brado este que repercutindo em Minas, arrastou as brasadas areias e inóspitos rochedos da África, entre outras vítimas, o ilustre canto de Marília de Dirceu [...]" (2011: 86-87, grifos nossos). 
A descrição continua elencando revoltas contra a condição colonial, como se uma seiva espontânea borbulhasse no país contra a dominação colonial, até resultar na própria independência. Lourenço se aproxima, neste pensamento, da geração romântica do IHGB, bem representada por Gonçalves de Magalhães, que se aproxima de uma crítica da civilização e busca perceber no indígena o elemento aglutinador do Brasil. É significativo que Lourenço busque no romance fortalecer o aspecto de memória e identidade do Brasil ligado às revoltas indígenas contra a condição colonial: dentre os grandes personagens que compuseram a "história de vultos" do Brasil, não se configura a presença individual de indígenas, silenciados, o que torna necessário ao Lourenço criá-los. Esta criação está entre o índio cavalheiro civilizado, perfeitamente pacífico e vivendo em belos bosques, e a sua neta mestiça, educada pelo melhor e mais manso intelecto missionário. Trata-se, mais do que aconteceu, do que Lourenço quer ver acontecido. Assim está dado o lugar dos indígenas na construção do Brasil, um dos principais elementos de reflexão do IHGB, que os jogavam entre a passividade irrefletida e a visão romântica do bom selvagem rousseauísta.

Quando Marcos/Severo se estabelece em nova fazenda, chamada de Remanso, reúne-se uma festa com vários elementos da sociedade luso-brasileira, entre militares, comerciantes e indígenas "cuja polidez, e decente tratamento habilitavam a concorrerem nas melhores reuniões do país" (2011: 136) - advertindo, mais uma vez ironicamente, que pode desapontar alguma "leitora solteirona, romântica estragada", ao comparar Abelardo com um "pobre indígena de Dari" (2011: 137). O "romântico estragado", presume-se, seria aquele que não consegue ver a dignidade dos personagens nacionais e seu heroísmo, perfeitamente comparáveis aos europeus. Na mesma passagem, Lourenço Amazonas se refere ao "imortal Macedo", outro sócio fundador do IHGB, e cujo romance Moreninha (1844) seguramente serviu para inspirar Simá. Aqui são discutidos novamente vários tópicos sobre a escravidão indígena e sobre o autoconcedido direito de posse dos europeus sobre os povos colonizados. Segundo este "direito feudal", uma bela e bem-educada mestiça não podia ser possuída por um indígena:

Os brancos principalmente, afeitos a considerar uma bela indígena, ou mameluca, como um direito feudal, ressentiam-se da impossibilidade, que lhes importava a solicitude e prevenção de Severo a par da habilitação de sua filha para compreender a sua dignidade: e este ressentimento crescia de ponto a ideia de que ela era destinada para o tálamo de um indígena. 
Domingos de sua parte desenvolvera-se assaz vantajosamente, assistindo-lhe todavia os predicados inerentes à sua raça. Sua tal ou qual instrução era sombreada pela modéstia, e sua polidez não atuava senão sob a capa da candura e da docilidade do indígena (2011: 145, grifos nossos).

O maniqueísmo na narrativa opõe a candura e docilidade do indígena à malícia e ao ressentimento presentes na aristocracia envilecida, da mesma forma como acontecia na poesia arcadista. O julgamento sumário em geral recai sobre o comerciante malintencionado, ajambrado pelo lucro - lembrando que o pai de Iaiá, melhor amiga de Simá, é um modesto caixeiro de Mariuá, portanto, pouco vinculado à busca pelo lucro. O realismo na descrição de algumas das paisagens é substituído pelo drama épico da conquista do interior, onde borbulha a vida nacional e os personagens espelham o revolucionário retornando para a natureza. Lourenço Amazonas está em busca do elemento autóctone tocado por contágios variados com a civilização que se movimenta pendularmente entre o bem e o mal. A doçura da índia aponta para o bem. É como se, no interior desse dualismo, a inocência indígena fosse o elemento diferencial da civilização brasileira.

Ao lado dos indígenas "polidos e decentes", Marcos/Severo é o "nativo com roupagem de cavalheiro" celebrado também por José de Alencar. Ao mesmo tempo em que transforma seus indígenas em cavalheiros, Lourenço Amazonas busca conferir um contorno realista à revolta indígena, colocando-a dentro da cronologia da independência, no que se aproxima da construção de uma memória histórica que sirva para autorizar o nascimento do Estado brasileiro. Em Juca Pirama (1851) de Gonçalves Dias, composta pouco tempo antes, o indígena aparece na agonia do estreitamento das fronteiras de sua cultura, "ganha perfil de herói humano, ao revelar, por meio da fraqueza e do choro, um lado antagônico do clássico herói oriundo das epopeias" (SANTOS, 2008: 150). Luzia Santos sugere que, em Gonçalves Dias, também um romancista e etnógrafo do IHGB, o esmagamento dos indígenas se dá "não pelo ritual antropofágico, em que o prisioneiro é devorado como símbolo da preservação da força e da coragem daquele que aprisiona, mas pela destruição da coletividade e da sua organização tribal, marginalizada pelo choque com o colonizador” (SANTOS, 2008: 125). O frei Raimundo, de origem carmelita, é o bom missionário da narrativa que busca adaptar o choque civilizatório à realidade indígena. Genuinamente brasileiro, ele 
luta ao lado do indígena contra a opressão. Ele é o bom educador rousseauísta, já que educa segundo a natureza e contra a escravidão:

o que importa aos brasileiros justamente um conceito: nisso que sentem conforme a natureza. Esta dita a todos os corações bem formados a compaixão pelo fraco e oprimido e a aversão ao forte, opressor. Observando a situação dos portugueses e dos indígenas, atendendo quanto o brasileiro participa da escravidão e menoscabo deste, claro fica que outro não poderá ser o seu sentimento (2011: 193, grifos nossos).

O mesmo frei Raimundo, num diálogo com elementos do mundo colonial (excluído daí o indígena), o comerciante (Régis) e o militar português (Olavo), diz, de forma irônica:

Que insolência de indígenas em se negar submeter-se a vosso domínio! Que amabilidade a vossa comparando-os hoje aos habitantes do resto do mundo, quando estão degradando-os da ordem em que os colocou a Providência, precisa foi a bula de um papa para vos obrigar a considerá-los gente! Que belo processo de os chamardes à civilização, entrando em suas malocas, atirando sobre os indóceis, e cativando os prisioneiros! Que bela sociedade, a que assim os convidastes, no patamar de vossa escada e no cabo de vossa enxada (2011: 194).

Frei Raimundo continua traduzindo as preocupações de Lourenço Amazonas com a formação da nação brasileira, preocupação que tem como pano de fundo a intelligentsia que se está formando em torno do IHGB. Para o frei, o Brasil foi "descoberto" por uma "nação inabilitada", deixando claro seu antilusitanismo. Sem condições de forjar uma consciência nacional, pela ausência de um sentimento patriótico, o resultado será, ainda segundo o Frei,

um estado tão equívoco entre a ignorância de sua prístina selvageria e a imoralidade de uma sociedade, minada pela corrupção antes de haver atingido a civilização. E um país, assim inabilitado para compreender, apreciar uma nacionalidade onde o patriotismo importará um ridículo, e as cívicas virtudes uma imbecilidade, não partilhará jamais em sua concorrência, com as demais nações, senão a lástima inerente à ideia de sua 
incoerência. À vista disso vede se vale a pena da vossa ironia a ideia de nossa futura independência? (2011: 195, grifos nossos).

O desfecho da narrativa, com a eclosão da revolta dos indígenas, acontece depois da "Assembleia de selvagens", onde Principais indígenas discutem a viabilidade de uma guerra contra os colonizadores. O indígena Dedari, favorável à guerra, sugere que a continuidade da civilização, nas condições atuais, implica subserviência, destruição de suas famílias e valores. Noutras palavras, conviverão com os vícios da sociedade, sem usufruir os benefícios da civilização:

Vossas mulheres, vossas filhas a despeito da consideração pelo seu estado, porque vos não deve ser extensiva a atenção pelo sagrado da família, serão empregadas nos serviços das nossas. Sereis considerados aptos para tudo quanto nós importe dificuldade, tédio e aversão. Sereis contrariados em todas vossas pretensões, tolhidos em vosso desenvolvimento, cerrados em vosso atraso e selvageria, para poderdes carregar com a increpação da indiferença pelas posições sociais, que reservamos para nosso exclusivo. Sereis increpados dos vícios e defeitos da sociedade, a que sois obrigados a pertencer, sem que a menor consideração vos aproveite pelas virtudes, com que porventura para ela possais concorrer. Sereis todos dedicação, préstimo, docilidade e sacrifícios, e havereis em compensação insulto, ridículo e desprezo (2011: 212).

A rebelião indígena é parte daquilo que mais tarde se chamará "espírito nacional", sublimado na luta pela independência, no caráter do povo brasileiro que não aceita a escravidão. Assim, a Amazônia aparece como parte de um todo indiviso da nação, ligado por essa herança que transparece como indiscutível do sangue indígena e da seiva revolucionária (PAIVA, 2010: 26). Ao compor o seu brasileiro, o seu elemento nacional, como de praxe entre os literatos do período, Lourenço Amazonas exclui os negros. No horizonte de ideias dos intelectuais do século XIX, considerar brasileiros os descendentes de portugueses e dos indígenas é considerar o que dizia a lei. Os negros, invisibilizados por esses letrados, pois precisavam desaparecer pela miscigenação, não gozavam do status de cidadania perante as leis. E, por isso, não podiam ser chamados de brasileiros. Em fala do personagem Régis, Lourenço manifesta que são "os brasileiros descendentes dos portugueses e dos indígenas" (AMAZONAS, 2011: 193). Sua 
composição étnica (aspectos figurativos fundamentais da narrativa nacional do período) estima um terço de habitantes africanos no território brasileiro ("com o qual se não deverá contar nunca para alarde de uma nacionalidade"). Também os portugueses, outro terço da população, não poderão ser úteis. Dentre os brasileiros restantes, em torno de dois milhões, há que se excluir aqueles educados pelo sistema "caviloso" dos jesuítas (Ibid.). Não resta, por fim, nenhuma esperança de que desse sistema “entorpecido" surja uma nação nos moldes europeus. O desfecho trágico da narrativa, com a morte de Simá no interior da Igreja de Santa Isabel, ilustra a dificuldade do autor em equacionar a questão nacional, ao contrário do que fará José de Alencar em seu indianismo.

\section{Considerações finais}

Depois da morte de Simá e do Frei Raimundo, quando Régis reconhece a sua filha bastarda em meio ao fogo, o governo do Grão-Pará decide reagir e sufocar a rebelião. O Grão Pará é a elite portuguesa sufocando a tal "seiva espontânea" da nação brasileira. Uma vez sufocada a revolta, volta-se à normalidade. Não há um heroísmo vencedor da guerra, como aconteceria na epopeia clássica. A heroína é a virgem inocente que morreu no fogo. A inocência, para Lourenço Amazonas é

a saúde da alma, a mais doce consolação, o mais suave bálsamo para as mais acerbas dores da vida, sua eficácia não poderá melhor resultar do que na virgem, que em semelhante atitude, e tão felizmente impressionada, em vez de uma criatura humana, se diria um daqueles seres bem-aventurados, que o autor do Apocalipse colocou ante o trono do Cordeiro em perene adoração (AMAZONAS, 2011: 261).

Quem se sobressai, portanto, é o cristianismo purificado, em auto expiação, diante do colonizador. Lourenço Amazonas se faz sobretudo um cristão. O romance trata da espinhosa integração da Amazônia por meio de seus indígenas, sua população autóctone, configurada em elemento central da brasilidade, na inocência que podia, devidamente educada, constituir uma futura civilização cristã purgada dos vícios europeus. Ao usar a Revolta de Lamalonga como pano de fundo do "romance histórico", Lourenço Amazonas buscou artifícios para superar a condição etnográfica e 
colocar o indígena na história, ainda que seja colocado na condição de Lorde Byroniano.

Como intelectual do IHGB, Lourenço buscou dar contornos à história brasileira e encontrar nela as raízes do homem nacional, viabilizando fatos e personagens do passado capazes de evocar a grandeza do pertencimento à nação, à consciência nacional, projeto conflituoso que implicava pensar o lugar dos subalternos na construção social do Brasil. É difícil crer que Lourenço tenha desempenhado o papel que queria, já que a sua produção literária foi pouco lida e mesmo pouco estudada. O que ele escreveu vale mais pela intenção do que pelo efeito: talvez antes de qualquer outro literato brasileiro, buscou pela inscrição da Amazônia interior, por meio de seus protagonistas indígenas, na história do Brasil.

\section{Referências bibliográficas}

AMAZONAS, Lourenço da Silva Araújo (1852). Diccionario topográfico, histórico e descriptivo da Comarca do Alto Amazonas. Recife: Tipografia Comercial de Meira Henriques.

AMAZONAS, Lourenço da Silva Araújo (2011). Simá. Romance histórico do AltoAmazonas. Manaus: Valer.

ANDERSON, Benedict (1989). Nação e consciência nacional. São Paulo: Ática.

Annaes do Parlamento Brasileiro (1850-1870), Rio de Janeiro.

AUSTIN, John Langshaw (1990). Quando dizer é fazer: palavras e ação. Porto Alegre: Artes Médicas.

BAULER, Almir e KLEIM, Ernesto (2011). “O discurso etnográfico na Revista IHGB”. Espaço Ameríndio, Porto Alegre, v. 5, n. 3, p. 66-84, jul./dez.

CANDIDO, Antonio (2006). Formação da literatura brasileira. Momentos decisivos. Rio de Janeiro: Ouro sobre azul.

COSTA, Daniel Padilha Pacheco (2016). "A história" da província do amazonas na obra de lourenço da silva Araújo". VIII Colóquio Internacional 'As Amazônias, as Áfricas e as Áfricas na Pan-Amazônia. Disponível em: https://periodicos.ufac.br/index.php/simposioufac/article/view/857/454 Acesso em Dez/2019.

DANTAS, Hélio (2011). Amazônia "revelada" e a Amazônia "interpretada". Diálogos, DHI/UEM, v. 5, n. 1, p. 11-47.

FAORO, Raimundo (2012). Os donos do poder. A formação do patronato político brasileiro. Rio de Janeiro: Ouro sobre azul.

FRÉMONT, Armand (1980). A região, espaço vivido. Coimbra: Almedina.

FURTADO, Marli Tereza (2012). "O Guarani e Simá: propostas para o romance brasileiro à escolha do leitor". XIII Encontro da ABRALIC Internacionalização do Regional. UEPB/UFCG - Campina Grande, PB.

GONDIM, Neide (1994). A Invenção da Amazônia. São Paulo: Marco Zero. 
GUIMARÃES, Manoel Luis Salgado (1988). "Nação e Civilização nos Trópicos: o Instituto Histórico e Geográfico e o Projeto de uma História Nacional". Estudos Históricos, Rio de Janeiro. Disponível em: http://www.cpdoc.fgv.br/revista/arq/26.pdf. Acesso em 15 de fevereiro de 2019.

HALL, Stuart (2005). A identidade cultural na pós - modernidade. Rio de janeiro: DP\&A.

JOBIM, Anísio (1934). A intelectualidade no Extremo norte: contribuições para a história da literatura no Amazonas. Manaus: Livraria Clássica.

JOBIM, Anísio (1957). O Amazonas, sua História. Ensaio antropogeográfico e político. Rio de Janeiro: Cia. Editora Nacional.

Jornal de Timon: Publicação Mensal (1853-1858), São Luís.

MALEVAL, Isadora (2019). "O Instituto Histórico e Geográfico Brasileiro como receptáculo do presente (1838-1850)". Topoi, Rio de Janeiro, vol.20, n.42, Sept./Dec. Disponível em http://dx.doi.org/10.1590/2237-101x02004205. Acesso em jan/2020.

NEVES, Lúcia Maria Bastos (2003). Corcundas e constitucionais. A cultura política da independência (1820-1822). Rio de Janeiro: Revan.

O Liberal Pernambucano (1852-1858), Recife.

Observador (1847-1861), São Luís.

ORLANDI, Eni (1993) Discurso fundador: A formação do país e a construção da identidade nacional. Campinas: Fontes.

PAIVA, Marco Aurélio Coelho (2010). O Papagaio e o fonógrafo. Os prosadores de ficção na Amazônia. Manaus: Fundação da Universidade do Amazonas.

QUEIROZ, Amilton José Freire (2009). Narrativas em trânsito: literatura, fronteira e lingua(gens) do Alto Amazonas no romance Simá. Dissertação de Mestrado, UFAC.

SAMPAIO, Patrícia Melo (2011). Anais do XXVI Simpósio Nacional de História ANPUH. São Paulo, julho. Disponível em https://anpuh.org.br/uploads/anaissimposios/pdf/2019-01/1548856708_16a11a9932612d550a664ffe1d48800a.pdf

SANTOS, Luzia Aparecida Oliva (2008). O percurso da indianidade na literatura brasileira: matizes da figuração. Tese apresentada à UNESP.

SKINNER, Quentin (1969). "Meaning and Understanding in the history of ideas". History and Theory Vol. 8, No. 1, p. 3-53.

Artigo recebido em 14 de janeiro de 2020.

Aprovado em 25 de novembro de 2020.

DOI: 10.12957/intellectus.2020.47785 